International Journal of Instruction e-ISSN: 1308-1470 • www.e-iji.net

Article submission code: 20201229221443

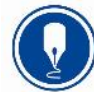

January $2022 \bullet$ Vol.15, No.1

p-ISSN: 1694-609X

pp. $837-856$

Received: 29/12/2020

Revision: 12/08/2021
Accepted: 06/09/2021

OnlineFirst: 05/12/2021

\title{
The Impact of Supplemental Word Recognition Strategies on Students with Reading Difficulties
}

\section{Gregory J. Benner}

Dr., The University of Alabama, United States of America, benner@ua.edu

Elizabeth Michael

The University of Alabama, United States of America, elizabeth.michael@ua.edu

\section{Nicole C. Ralston}

University of Portland, United States of America, ralston@up.edu

Erica O. Lee

The University of Alabama, United States of America, eolee1@ua.edu

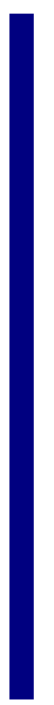

The purpose of this study was to examine the impact of supplemental word recognition strategies on students receiving intensive (Tier III) remedial reading instruction. Two-hundred and thirteen middle school students with reading difficulties received an intensive reading intervention (i.e., Corrective Reading Decoding strand) delivered by trained school staff $(n=21)$ at three middle schools. The 213 fifth through eighth grade students (121 males, 92 females) enrolled in three northwestern school districts (two rural and one urban). Of the 213 students, one-hundred and seven also received supplemental word recognition instruction using Reading Excellence: Word Attack and Rate Development Strategies (REWARDS). Using a pre-post quasi-experimental design, the effects of the Corrective Reading Decoding (CRD) program was compared to CRD combined with the REWARDS program. The REWARDS program produced statistically and educationally significant changes in the basic reading skills of students over and above Corrective Reading Decoding alone. Students in the REWARDS condition demonstrated statistically significant mean changes on the WJ-III Basic Reading Skills cluster and associated subtests and the DIBELS ORF probe compared to those in the comparison condition. Results, implications, and limitations are discussed.

Keywords: remedial reading instruction, word reading strategies, reading intervention, reading instruction, adolescent literacy, intensive reading instruction

\section{INTRODUCTION}

Problems with literacy have contributed to generational disproportionality for decades in the United States. Without the basic ability to read and write, students are met with significant barriers to future employment and economic success. In 2017, only $36 \%$ of

Citation: Benner, G. J., Michael, E., Ralston, N. C., \& Lee, E. O. (2022). The impact of supplemental word recognition strategies on students with reading difficulties. International Journal of Instruction, 15(1) 837-856. https://doi.org/10.29333/iji.2022.15148a 
eighth graders in the United States were at or above "proficient" levels in reading and $76 \%$ at or above "basic" levels on the National Assessment of Educational Progress (NAEP) report (U.S. Department of Education, 2017). Only 34\% percent of eighth graders in the United States were at or above "proficient" levels and $73 \%$ at or above "basic" levels on the National Assessment of Educational Progress (NAEP) report in 2019. Statistically significant declines were found in the reading performance of $8^{\text {th }}$ grade youth from 2017 to 2019 (U.S. Department of Education, 2019).

Most middle school students struggle reading grade level text with ease and understanding. Researchers provide a strong rationale for building literacy skills in the context of improving overall quality of life, such as increased inclusive opportunities, social relationships, self-determination, internet access, and improved employment opportunities (Browder et al., 2009; Cihak \& Smith, 2018; Kamil et al., 2008). Reading difficulties contribute to retention, qualification for special education services, unemployment, social and emotional problems, and adjudication (e.g., Burke et al., 2015; Campbell et al., 2018; Garwood, 2018; Marchand-Martella et al., 2013; Rumberger et al., 2017). Considering the enormous impact of literacy on student success, it is imperative for schools to prioritize this issue.

To tackle literacy difficulties in the United States and to enhance college and career readiness, the Common Core State Standards in English Language Arts (National Governors Association Center for Best Practices, Council of Chief State School Officers, 2012) were created. Currently 46 states, the District of Columbia, and three other territories have adopted a common framework of English Language Arts standards in reading, writing, language, speaking and listening, and technical subjects, such as science and history. Core and comprehensive reading programs, along with strategic and intensive interventions, now speak to their alignment to the Common Core State Standards (CCSS) in English Language Arts (ELA). The ACT, Inc. released a report entitled Reading Between the Lines (2006), indicating that students who equaled or exceeded benchmark scores on the ACT could answer complex text level questions; however, since the release of that report there has been a steady decline regarding text complexity levels in students in the United States. Williamson (2006; as cited in National Governors Association Center for Best Practices, Council of Chief State School Officers, Appendix A, 2012) reported a standard deviation gap of 1.5 between the end-of-high school and the beginning of college level text. Thus, students who enter college are already considered statistically behind when it comes to reading collegelevel textbooks and materials.

The Simple View (SV) theory of reading development emphasizes that reading is the product of both decoding and language comprehension (Gough \& Tunmer, 1986). Skilled readers effortlessly process the complete spellings of words, allowing the reader to focus cognitive energy on comprehension; as students become skilled readers, separate skill strands within and across both word recognition and language comprehension gradually become more entwined (Scarborough, 2001). Empirical research with typically developing readers indicates reading is a highly integrated process, rather than a set of isolated skills. Even during isolated word recognition tasks, 
skilled readers link words to word meanings and use meaning to increase fluency and verify correct identification of words when reading text (Adams, 1990, 2013).

Researchers have found that systematic and explicit reading instruction provided to struggling readers and those with reading disabilities can improve lifelong literacy outcomes (e.g., Foorman et al., 2016; Partanen \& Siegel, 2013; Wanzek et al., 2015; Wanzek et al., 2018). Regardless of the deficit, nine guidelines are relevant to teaching remedial reading (Carnine et al., 2017). These guidelines are as follows: (1) intervene early; (2) provide extra instructional time; (3) use small-group instruction; (4) use effective instructional materials; (5) create a comprehensive, aligned program; (6) administer progress-monitoring assessments frequently; (7) group for maximum efficiency; (8) include a motivational component; and (9) ensure that teaching personnel are well trained. Additionally, Carnine et al. (2017) offer 12 basic principles for educators to follow when providing reading instruction to older students who are significantly behind their grade-level peers. These principles include: (1) spelling and writing aligned with reading instruction, (2) explicit and systematic instruction, (3) highly aligned instruction, (4) essential skills prioritization, (5) age appropriateness, (6) design that ensures faulty strategies are fixed, (7) placement testing and frequent progress monitoring, (8) constant communication among staff about students, (9) instruction that begins as soon as possible, (10) adequate instructional time within programming, (11) emphasis on vocabulary and comprehension, and (12) a motivational component. Again, careful attention should be paid to the ELA CCSS to ensure that students are building pertinent college and career literacy readiness skills.

Word study, fluency, vocabulary, comprehension, and motivation are important instructional components for older students (Boardman et al., 2008). Fluency, vocabulary, and comprehension overlap with those components recommended for students in grades K-3. Thus, when working with older students, it would be relevant to provide instruction related to these areas, as well as including more informational and advanced literacy with a higher level of text difficulty. Word recognition is a new component for students in grades 4-12. For these older students, a focus placed on decoding words is an important aspect of English Language Arts; however, these words are more often found in tougher text such as science and social studies. The key to decoding multisyllabic words such as "reconstruction," is to break the words into smaller parts that have at least one vowel sound (re/con/struc/tion), say the parts slowly, and then say them to form a word. Additionally, work should take place with prefixes, suffixes, root words and their meanings (to link to vocabulary) with a focus on individual sound and blending as a priority if students are lower-level readers in terms of decoding (reading to learn).

Additionally, study skills and strategies should be taught to students (Dunlosky, 2013). Study skills and strategies should focus on teaching students how to take notes from text and lecture, how to self-test (i.e., asking themselves questions based on notes/index cards/end-of-chapter questions), and how to use what was highlighted or re-read in meaningful ways. One such strategy known to assist struggling readers is the practice of repeated reading (Lee \& Yoon, 2017). In this strategy, students with decoding skills 
participate in repeated readings of the same text to foster growth in reading fluency. During a repeated reading activity, a student reads a text aloud multiple times in a row. This typically takes place a minimum of three times or until the student reaches a predetermined set of mastery criteria. A teacher or peer partner participates with the student to assist with the activity. When a word is mispronounced or the student hesitates more than five seconds, the teacher or partner reads the word aloud for the student to repeat correctly. Repeated reading, a generalizable strategy, can be applied to content areas such as language arts or science (Archer et al., 2003). Researchers of two studies that met What Works Clearinghouse (WWC) group design standards without reservations have identified repeated readings as having potentially positive effects on reading comprehension (Ellis \& Graves, 1990; Wexler et al., 2010).

Research supports direct instruction reading programs (see reviews by Adams \& Engelmann, 1996; White, 1988). One example of this is through the strategy of Corrective Reading, a program for students in grades three and above who are reading below grade-level. Przychodzin-Havis et al. (2005) have proven that this program can be implemented with fidelity by both certified (i.e., general and special education teachers) and non-certified professionals (e.g., paraprofessionals), as well as nonprofessionals (e.g., tutors). When studied in comparison to other direct instruction programs, students who participated in Corrective Reading outperformed students in comparison groups, as noted in standardized and curriculum-based reading measures (Benner et al., 2005; Lloyd et al., 1980; Somerville \& Leach, 1988; Thomson, 1992).

In the present investigation, we examine the impact a direct instruction program called Reading Excellence: Word Attack \& Rate Development Strategies (REWARDS; Archer et al., 2003), a reading program designed for students in grades 4-12 who struggle with basic reading decoding, including difficulty with multisyllabic words found in contentarea texts. While researchers have published two peer-reviewed articles detailing the development of this program (Archer et al., 2000; 2003) and one master's thesis (Butler, 2014), there are no peer-reviewed studies of this program, to date. Given that researchers have not conducted experimental studies of the Reading Excellence: Word Attack \& Rate Development Strategies program, the present investigation fills a significant gap in the evidence-base by conducting a quasi-experimental investigation of REWARDS. The purpose of this study was to evaluate the effects of the Corrective Reading Decoding (CRD) program alone compared to CRD combined with the Reading Excellence: Word Attack \& Rate Development Strategies program (REWARDS; Archer et al., 2000).

\section{METHOD}

\section{Participants}

Three school districts from the northwestern United States participated in this study. The participants included 213 fifth through eighth grade students (121 males, 92 females) from one urban and two rural school districts. The three middle schools participating were designated as "high need" by the state of Washington due to low overall academic achievement. It is important to note that all the students who received the Corrective 
Reading Decoding strand were experiencing word reading skill problems (Engelmann et al., 2002). As described in Table 1, the number and associated percentages of students enrolled in the fifth, sixth, seventh, and eighth grades at the time of screening were 11 $(5 \%), 85(40 \%), 70(33 \%)$ and $47(22 \%)$, respectively. Forty-six (22\%) of these students (27 males, 19 females) received special education services for a variety of disabilities (i.e., Learning Disability, Emotional Disturbance, Other Health Impairment, Intellectual Disability).

\section{Screening and Placement}

The identification of participants included a two-step process. Initially, all fifth through eighth grade students in the participating schools were screened by trained school staff. The universal screening measure was the Dynamic Indicators of Basic Early Literacy Skills (DIBELS) Oral Reading Fluency (ORF) fifth or sixth grade level fluency probes (Kaminski \& Good, 1996). These probes were administered and scored by middle school teachers who had been observed administering and scoring such probes with at least $90 \%$ integrity. Overall integrity of DIBELS ORF administration and scoring was 97\%. Fifth grade DIBELS ORF fluency probes were used for fifth grade students; whereas, sixth grade DIBELS ORF fluency probes were used for sixth through eighth grade students The Reading Response to Intervention (RTI) teams at each middle school agreed to use sixth grade DIBELS ORF passages to screen seventh and eighth graders for the following reasons: 1) DIBELS are free (the team was unable to find any free seventh and eighth grade ORF passages and DIBELS does not offer ORF passages for these grade levels); 2) DIBELS are easily accessible; and 3) the purpose in using sixth grade level probes was to identify students who may be experiencing reading difficulties. It is important to note that the DIBELS ORF probes were not used to diagnose or evaluate outcomes of the Corrective Reading Decoding program. In all cases, three unique DIBELS ORF fluency probes were administered to students in sequence and the median scores (i.e., correct words per minute) were used to determine initial eligibility for participation. Students whose median score was categorized as "atrisk" by DIBELS (University of Oregon Center on Teaching and Learning, 2020) participated. These "at risk" scores by grade level were: fifth $(<103)$, sixth $(<104)$, seventh $(<125)$, and eighth $(<125)$, respectively. The mean DIBELS ORF probe scores for fifth through eighth grade students were $64.5(S D=20.2), 66.2(S D=19.01), 80.4$ $(S D=22.9)$, and $86.2(S D=26.4)$, respectively.

The Corrective Reading Decoding Placement Test was used to continue student identification for students whose DIBELS ORF scores fell in the "at-risk" category to ensure that the Corrective Reading Decoding strand was appropriate for addressing their word reading skill problems (see https://www.nifdi.org/resources/freedownloads/programs/reading-2/corrective-reading-1/placement-testing-1/722-

corrective-reading-decoding-placement-test/file.html for a copy of the Placement Test). Established criteria of the Decoding Placement Schedule of the Corrective Reading Decoding Placement Test was used to determine whether the Corrective Reading Decoding intervention was appropriate and what level was the best placement for the student. In other words, homogenous groups were established using the results of the 
Corrective Reading Decoding Placement Test and students were placed in the appropriate level (B1, B2, or C) of the Corrective Reading Decoding strand.

Teachers of students placed into Corrective Reading Level B1 completed 65 lessons of B1, Corrective Reading B2 (65 lessons), then ended the academic year in Corrective Reading Level C (125 lessons). Teachers of students placed into Corrective Reading B2 completed 65 lessons of Corrective Reading Level B2, 20 lessons of REWARDS, then ended the academic year in Corrective Reading Level C (125 lessons). Teachers of students placed into Corrective Reading C started with REWARDS (20 lessons), then ended the academic year in Corrective Reading Level C (125 lessons).

\section{School Settings}

\section{School 1}

Fifty-three (25\%) of the 213 study participants were enrolled in School 1. School 1, a rural middle school, served 222 students in grades five through eight. The Corrective Reading Decoding strand and REWARDS was taught to the participants by three general education teachers. Their mean years of teaching experience was $6.0(S D=3.6$; Range $=2$ to 9$)$, and their mean years of experience teaching reading was $3.7(S D=2.9$; Range $=2$ to 7 ).

\section{School 2}

Forty-five (21\%) of the 213 study participants were enrolled in School 2. School 2, a rural middle school, served 250 students in grades six through eight. The Corrective Reading Decoding strand and REWARDS was taught to the participants by two instructional specialists and two paraprofessionals. The mean years of teaching or educational (in the case of the paraprofessionals) experience were $14.0(S D=5.0$; Range $=8$ to 20$)$. The mean years of experience teaching reading were $10.8(S D=8.1$; Range $=3$ to 20$)$.

\section{School 3}

One hundred fifteen (54\%) of the 213 study participants were enrolled in School 3. School 3, an urban middle school, served 585 students in grades six through eight. The Corrective Reading Decoding and Reading Excellence: Word Attack and Rate Development Strategies (REWARDS) was taught to the participants by eleven general education teachers, two special education teachers, and one instructional specialist. Their mean years of teaching experience was $10.6(S D=9.0$; Range $=2$ to 34$)$. Their mean years of experience teaching reading was $4.6(S D=6.2$; Range $=0$ to 16). Table 1 further describes the demographics of participating schools. 


\begin{tabular}{|c|c|c|c|c|c|c|c|c|}
\hline \multirow[b]{2}{*}{ Group } & \multicolumn{4}{|l|}{ Ethnicity } & \multicolumn{4}{|l|}{ Services } \\
\hline & Caucasian & $\begin{array}{l}\text { American } \\
\text { Indian / } \\
\text { Alaskan } \\
\text { Native }\end{array}$ & $\begin{array}{l}\text { African } \\
\text { American }\end{array}$ & Hispanic & $\begin{array}{l}\text { Asian } \\
\text { American }\end{array}$ & $\begin{array}{l}\text { Special } \\
\text { Education }\end{array}$ & $\begin{array}{l}\text { Free/ } \\
\text { Reduced } \\
\text { Lunch }\end{array}$ & $\begin{array}{l}\text { English } \\
\text { Language } \\
\text { Learner }\end{array}$ \\
\hline Student & & & & & & & & \\
\hline $\begin{array}{l}\text { Participants } \\
\text { CR }(\mathrm{n}=106)\end{array}$ & $57 \%$ & $26 \%$ & $4 \%$ & $13 \%$ & NA & $22 \%$ & $56 \%$ & $12 \%$ \\
\hline $\begin{array}{l}\text { Rewards/CR } \\
(\mathrm{n}=107)\end{array}$ & $49 \%$ & $7 \%$ & $26 \%$ & $14 \%$ & $5 \%$ & $22 \%$ & $55 \%$ & $13 \%$ \\
\hline $\begin{array}{l}\text { School } 1 \quad(n= \\
115)\end{array}$ & $53 \%$ & $1 \%$ & $27 \%$ & $15 \%$ & $4 \%$ & $23 \%$ & $53 \%$ & $13 \%$ \\
\hline School $2(n=53)$ & $45 \%$ & $51 \%$ & $2 \%$ & $2 \%$ & NA & $22 \%$ & $60 \%$ & $10 \%$ \\
\hline School $3(n=45)$ & $60 \%$ & $16 \%$ & NA & $24 \%$ & NA & $18 \%$ & $59 \%$ & $13 \%$ \\
\hline
\end{tabular}

Table 1

The demographics of participating schools

Note. $\mathrm{N} / \mathrm{A}=$ Information not available

Note. ${ }^{* * *} \mathrm{p}<.001, * * \mathrm{p}<.01, * \mathrm{p}<.05$. The WJ-III scores were standard scores based upon a normal curve $(M=100 ; S D=15)$. Effect sizes were based on Cohen's (1988) guidelines, stating that scores ranging from 0 to 0.3 are considered small, 0.3 to 0.8 are moderate, and all scores above .8 are large. ${ }^{a} \mathrm{~A}$ total of 85 of $\mathrm{CR}$ and $99 \mathrm{CR} / \mathrm{RW}$ students received pre- and post-test DIBELS ORF.

\section{Interventions}

Corrective Reading (Engelmann et al., 2002) is a direct instruction reading program for students in third through twelfth grades who are performing at least one year below grade level in reading. This program is made up of two major strands: Decoding and Comprehension. Three essential instructional goals of the Decoding strand are to develop decoding, word reading, and fluency skills and concepts. The Comprehension strand focuses on developing vocabulary and comprehension skills and concepts.

The study utilizes Corrective Reading Decoding strand chosen over other reading programs due to its broad research base demonstrating the program's potential to improve reading achievement (Benner, 2007; Benner et al., 2005; Lloyd et al., 1980; Marchand-Martella et al., 2000). Comprised of four levels, Corrective Reading Decoding is comprised of four levels (Levels B1, B2, and C). Fifty-five students (19\%) were initially placed in Level B1, $213(76 \%)$ were placed in Level B2, and $13(5 \%)$ were placed in Level C. Levels B1 and B2 are each comprised of 65 lessons each that take 40 to 45 minutes to complete. Level $\mathrm{C}$ is comprised of 140 lessons that take 40 to 45 minutes to complete. The program materials for each level included (a) a teacher book containing a script for each lesson; (b) a pacing guide and placement tests; (c) a non-consumable student book containing word lists, story selections, and informational articles; (d) a consumable student workbook containing teacher directed and independent student activities that align with each lesson; and (e) a separate workbook answer key. Teachers used stopwatches, dry erase boards, markers, pencils, and folders to track the progress of students in addition to the program material. Students also tracked their own progress of points earned and fluency scores (Engelmann et al., 2002).

The four general parts to the lessons in Levels B1, B2, and C include: (a) word attack skills (10 minutes); (b) group reading (10-15 minutes); (c) individual reading (10 minutes); and (d) workbook exercises (10 minutes). Word attack consisted of students practice pronouncing words, identifying the sounds and sound combinations, and 
reading isolated words composed of sounds and sound combinations (Englemann et al., 2002). After the word attack activities, group reading took place and students took turns reading aloud from their student book while students who were not reading followed along. Individual reading followed the group reading activity and assigned pairs of students read two passages. The first was from lesson the group just read, and the second passage was from the preceding lesson. Individual students read the passage from the lesson the group just read and then the passage from the preceding lesson. The last part of the lesson consisted of completion of Workbook exercises.

Reading Excellence: Word Attack and Rate Development Strategies (REWARDS; Archer et al., 2000) is a research-validated reading program designed for students in grades 4-12 who struggle in basic reading decoding, including difficulty with word recognition, particularly with words found in content-area texts (Voyager Sopris Learning, 2020). The core objectives are to increase decoding, fluency, vocabulary, comprehension, test-taking skills, content-area reading and writing, word choice, and sentence writing and revision skills. REWARDS is designed specifically for students who have mastered skills associated with first- and second grade reading but have difficulty reading long words and/or who read slowly (i.e., 60 to 120 correct oral words per minute). In contrast to $\mathrm{CR}$, which was designed for students reading below a 2.5 grade level, REWARDS is designed to be an intense, short-term program for struggling secondary readers reading between a 2.5 and $5^{\text {th }}$ grade reading level (Archer, Gleason, \& Vachon, 2003).

The authors of REWARDS indicate the goal is to teach students a flexible strategy for decoding long words that are both effective and efficient (Archer et al., 2003). Students learn to segment long words into decodable parts by circling word parts (prefixes) that come at the beginning of the word or at the end of the word (suffixes). Students learn to underline vowel sounds in the rest of the word. Students then say the parts, say the whole word, and finally make it a real word. With practice, students look for word parts at the beginning and end of the word and for vowel sounds in the rest of the word. They learn to say the parts, say the parts fast, and make it a real word. In REWARDS, students are directly taught phoneme-grapheme correspondences for vowels and affix pronunciations through modeling, practice, and daily review (Archer et al., 2003).

\section{Dependent Measures}

Two dependent measures basic reading skills and reading fluency were used in this study: The Woodcock-Johnson: Tests of Achievement, Third Edition (WJ-III) (Woodcock et al., 2001) and the Dynamic Indicators of Basic Early Literacy Skills (DIBELS) (Kaminski \& Good, 1996) Oral Reading Fluency (ORF) probe (see below for descriptions).

WJ-III

The WJ-III Basic Reading Skills cluster was used to measure participants' basic reading skills, which includes the Letter-Word Identification and Word Attack subtests. In the Letter-Word Identification subtest, students orally read letters and words presented in isolation to assess their abilities with sight vocabulary, decoding, and structural analysis. 
In the Word Attack subtest, students decode and read aloud a series of nonsense words to assess their phonics and decoding skills.

Test-retest reliability coefficients of the Basic Reading Skills cluster, the Letter-Word Identification subtest, Word Attack subtest, and Passage Comprehension subtest are .95, .94, .87, and .88, respectively. All students were administered the WJ-III Basic Reading cluster and the Passage Comprehension subtest in the spring prior to the implementation year (baseline) and the spring of the implementation year.

\section{DIBELS}

The DIBELS ORF probe assesses the student's accuracy and fluency with connected text. To administer the ORF probe, the teacher presents the student with a reading passage of approximately 250 words. The passages are calibrated for the goal level of reading for each grade level. The student is then asked to read the passage aloud for one minute. Words omitted or substituted, and hesitations of more than three seconds are scored as errors. Words read correctly or self-corrected within three seconds are scored as accurate. Test-retest reliabilities for elementary students ranged from .92 to .97; alternate-form reliability of different reading passages drawn from the same level ranged from .89 to .94 (Deno et al., 2001; Tindal et al., 1983). To increase the reliability of the DIBELS ORF probe, examiners conducted three different passages and calculated the median words read correctly per minute for each student at pre- and posttest. Students who were provided the Corrective Reading Decoding Level B1 and B2 and their comparison counterparts received the DIBELS ORF $3^{\text {rd }}$ and $4^{\text {th }}$ grade passages, respectively. All participating and comparison condition students were administered the same third or fourth grade DIBELS ORF probes at pre- and posttest.

Scoring agreement checks on all WJ-III and DIBELS ORF protocols were conducted. Each protocol was checked for scoring accuracy by the first author of this article after initial scoring by student teachers. Agreement was calculated by dividing the number of agreements by divided by agreements plus disagreements and multiplying by 100 . When the agreement checks calculations aligned with calculations made at initial scoring, an agreement was recorded. Agreement in scoring WJ-III protocols and DIBELS ORF protocols was $98 \%$ (range $=96 \%$ to $100 \%$ ), and $99 \%$ (range $=98 \%$ to $100 \%$ ), respectively.

\section{Assessment Integrity}

The DIBELS Oral Reading Fluency Integrity Checklist and WJ-III Assessment Integrity Checklist were used to determine the degree to which dependent measures were administered as intended. Assessment of data collectors took place at two time points: Pre-testing, and Post-Testing. Administrator assessment integrity of DIBELS ORF at Pre-and Post-Testing was $99.3 \%$ and $100.0 \%$, respectively. Administrator assessment integrity of WJ-III at Pre-and Post-Testing was $97.2 \%$ and $98.5 \%$, respectively.

\section{Fidelity of Implementation}

A Corrective Reading Decoding and REWARDS Fidelity of Implementation Observation checklist was used to ascertain fidelity of implementation (see Figure 1). 
The checklist was developed by seven experts on the Direct Instruction reading programs, including Corrective Reading Decoding and REWARDS. Expert contributions to the development of the fidelity checklist were provided by the lead author of this article and the trainer of the participating teachers (see Professional Development section below). Additional contributions included researchers and consultants with Corrective Reading Decoding and REWARDS. The process started with identifying a Corrective Reading and REWARDS fidelity checklist used by trainers and coaches implementing these programs in middle schools. Three Corrective Reading Decoding and REWARDS experts revised the checklist until consensus on content validity was reached. After significant review and iteration, all experts agreed upon the five teacher actions and the Likert-scale format for rating them. After reaching consensus on content validity according to experts on the Corrective Reading Decoding and REWARDS programs, the checklist was then sent to participating teachers $(n=21)$ at each of the middle schools for feedback after these individuals had received a full day of training and had practiced the program. Teacher feedback was incorporated, and all participating teachers agreed that the content and format of the Corrective Reading Decoding Fidelity of Implementation Observation checklist was valid.

\section{Observation Checklist}

The checklist (see Figure 1) targeted five teacher actions critical to the implementation of the Corrective Reading Decoding and REWARDS programs: 1) Follows the lesson format, 2) uses specific praise statements and feedback, 3) monitors student responses, 4) re-teaches when needed, and 5) uses established error correction procedures. The first teacher action (i.e., follows the lesson format) focused on adherence or the extent to which the lessons were delivered as designed; whereas the remaining actions centered on quality of implementation (i.e., lessons delivered using the prescribed techniques, processes, and methods). Observers rated each of the five teacher actions on a 5-point Likert-type scale ranging from zero ( 0 ; does not cover component at all during lesson) to five (5; covers component well during lesson). Actions observed between these two spectrums received scores between zero and five accordingly. Each observation yielded an overall score ( 0 to 25 ) and separate scores for each of the five teacher actions ( 0 to 5). Fidelity of implementation observations were conducted both by the professional development trainer and the literacy coaches. Subsequently, Pearson Product Moment correlations were used to estimate inter-rater reliability between the observation results conducted by the trainer and those conducted by the literacy coaches. For both programs, the inter-rater reliability coefficient for the overall fidelity of implementation score was .87. The inter-rater reliability coefficients for the "follows the lesson format," "uses specific praise statements and feedback," "monitors student responses," "reteaches when needed," and "uses established error correction procedures" teacher actions were $.71, .75, .79, .90$, and .72 , respectively. It is important to note that although these inter-rater reliability results may be affected by literacy coach bias, the coaches were not involved in the collection of student data. All teachers, however, were observed by the trainer. Thus, for this study, the observation conducted by the trainer was used for the analyses. 


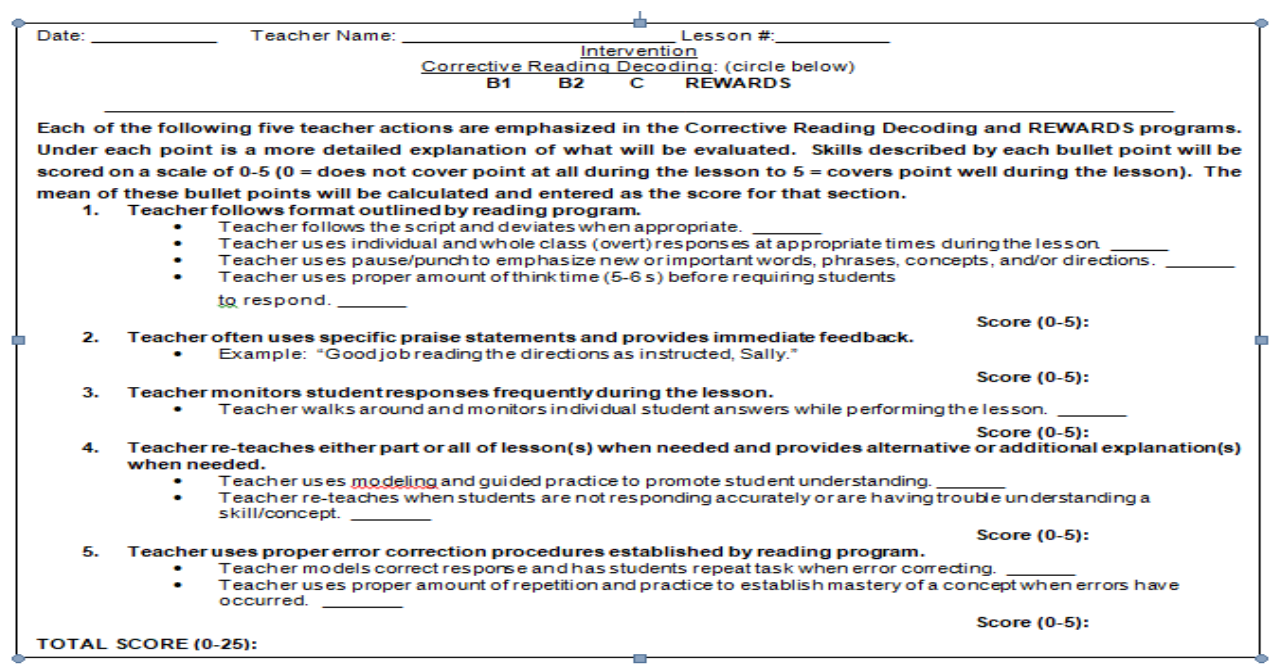

Figure 1

Observation checklist

\section{Professional Development}

An initial one-day workshop, two onsite coaching visits, and a half-day booster training session were conducted by project staff to train teachers and other relevant school personnel involved in the study. The trainer had 15 years of experience using and training teachers on Direct Instruction programs including the Corrective Reading Decoding strand and REWARDS. A one-day workshop was conducted to train teachers on the placement system, instructional methods, corrective feedback procedures, and monitoring systems. The teachers were also provided with practice opportunities implementing the Corrective Reading Decoding strand and REWARDS. Project staff conducted two onsite follow-up coaching visits at each school during the school year. During these follow-ups, the teachers were observed, feedback was provided, and student progress was discussed. During an additional half-day booster training, project staff provided further instruction to address instructional procedures (i.e., pacing, scripts) and adjustments to meet students' individual needs.

\section{Research Design}

A pre-post quasi-experimental design (Martella et al., 1999) was used to examine the effects of the Corrective Reading Decoding (CRD) program alone compared to CRD combined with the REWARDS program.

\section{Analyses}

There were two primary analyses in this investigation. Analyses of Covariance (ANCOVA) were used initially to determine if the differences in the posttest scores of participating and comparison students were statistically significant using pretest scores as a covariate. Second, effect size estimates were used to determine the statistical 
significance of Corrective Reading (CR) and Corrective Reading plus Rewards $(\mathrm{CR}+\mathrm{RW})$. Effect sizes were interpreted using Cohen's guidelines (1988), in which an effect size of 0.2 is small, 0.5 is medium, and 0.8 or greater is large.

\section{FINDINGS}

To examine whether there were statistically significant differences in the posttest means of the basic reading skills of students in the Corrective Reading and Corrective Reading (CR) and REWARDS (CR+RW), ANCOVAs were conducted with pretest scores serving as the covariate. A statistically significant main effect for condition (i.e., participating and comparison) was obtained in all cases. There were no other statistically significant main or interaction effects. Mean pre- and post-intervention standard scores, change scores, associated F-statistics for the main effect for condition, and effect sizes are presented in Table 2. Analysis of Table 2 reveals that students in the CR+RW condition showed statistically significant improvements in their basic reading relative to students in the CR condition (WJ-III Basic Reading Skills Cluster: $F[1,106]=12.1$, p $<.01)$, word attack $(W J-I I I$ Word Attack: $F[1,106]=13.4, \mathrm{p}<.001)$, and oral reading fluency (DIBELS ORF probe: $F[1,106]=5.6, \mathrm{p}<.05)$ skills. Effect size estimates based on the mean change scores of $\mathrm{CR}$ and CR+RW students on the WJ-III Word Attack subtest $(\mathrm{ES}=.50)$ scores were moderate in magnitude. The effect size estimates based on the mean change scores of participating and comparison students on the WJ-III Basic Reading Skills Cluster $(\mathrm{ES}=.48)$, DIBELS ORF $(\mathrm{ES}=.39)$, and Passage Comprehension $(E S=.21)$ subtest were small in magnitude. Thus, effect sizes on these reading measures were deemed educationally significant, whereas those on the WJ-III Letter Word Identification $(\mathrm{ES}=.18)$ subtest was trivial in magnitude and not educationally significant.

Table 2

Mean pre- and post-intervention standard scores

\begin{tabular}{|c|c|c|c|c|c|c|c|c|}
\hline \multirow[b]{2}{*}{ Measure } & \multicolumn{3}{|c|}{$\begin{array}{l}\text { Corrective Reading } \\
(\mathrm{n}=106)\end{array}$} & \multicolumn{5}{|c|}{$\begin{array}{l}\text { CR plus REWARDS } \\
(\mathrm{N}=107)\end{array}$} \\
\hline & Pre & Post & Change & Pre & Post & Change & $\mathrm{F}$ & Effect Size \\
\hline $\begin{array}{l}\text { WJ-III Basic Reading } \\
\text { Skills }\end{array}$ & $\begin{array}{l}89.6 \\
(9.6)\end{array}$ & $\begin{array}{l}92.5 \\
(9.9)\end{array}$ & $\begin{array}{l}2.9 \\
(4.1)\end{array}$ & $\begin{array}{l}91.6 \\
(7.7)\end{array}$ & $\begin{array}{l}96.7 \\
(9.1)\end{array}$ & $\begin{array}{l}5.0 \\
(4.8)\end{array}$ & $12.7 * *$ & .48 \\
\hline $\begin{array}{l}\text { Letter-Word } \\
\text { Identification }\end{array}$ & $\begin{array}{l}88.0 \\
(12.2)\end{array}$ & $\begin{array}{l}91.2 \\
(11.1)\end{array}$ & $\begin{array}{l}3.3 \\
(5.5)\end{array}$ & $\begin{array}{l}90.4 \\
(7.6)\end{array}$ & $\begin{array}{l}94.6 \\
(8.6)\end{array}$ & $\begin{array}{l}4.2 \\
(5.2)\end{array}$ & 1.8 & .18 \\
\hline Word Attack & $\begin{array}{l}92.0 \\
(8.6)\end{array}$ & $\begin{array}{l}94.1 \\
(9.4)\end{array}$ & $\begin{array}{l}2.1 \\
(6.0)\end{array}$ & $\begin{array}{l}93.3 \\
(9.0)\end{array}$ & $\begin{array}{l}98.6 \\
(10.3)\end{array}$ & $\begin{array}{l}5.3 \\
(6.8)\end{array}$ & $13.4 * * *$ & .50 \\
\hline $\begin{array}{l}\text { Passage } \\
\text { Comprehension }\end{array}$ & $\begin{array}{l}87.3 \\
(9.3)\end{array}$ & $\begin{array}{l}91.2 \\
(9.2)\end{array}$ & $\begin{array}{l}3.9 \\
(7.0)\end{array}$ & $\begin{array}{l}88.1 \\
(7.6)\end{array}$ & $\begin{array}{l}93.4 \\
(8.5)\end{array}$ & $\begin{array}{l}5.3 \\
(6.9)\end{array}$ & 2.3 & .21 \\
\hline DIBELS ORF probe ${ }^{\mathrm{a}}$ & $\begin{array}{l}66.0 \\
(22.0) \\
\end{array}$ & $\begin{array}{l}87.3 \\
(28.7) \\
\end{array}$ & $\begin{array}{l}21.3 \\
(15.2)\end{array}$ & $\begin{array}{l}81.0 \\
(22.3) \\
\end{array}$ & $\begin{array}{r}108.3 \\
30.0)\end{array}$ & $\begin{array}{l}27.3 \\
(15.5)\end{array}$ & $5.6^{*}$ & .39 \\
\hline
\end{tabular}




\section{DISCUSSION}

Most middle school students struggle reading grade level text with ease and understanding. Reading difficulties are closely associated with school dropout, unemployment, and failure in college (Marchand-Martella et al., 2013). To date, Researchers have not examined the impact of the REWARDS program. In this context, the purpose of this study was to examine the effects of the Corrective Reading Decoding (CRD) program alone compared to CRD combined with the Reading Excellence: Word Attack \& Rate Development Strategies (REWARDS; Archer et al., 2000) program. We partnered with three high need middle schools with low overall academic achievement to explore the impact of explicit and systematic remedial reading instruction on youth with word reading skill problems.

Several findings from the study warrant discussion. The REWARDS program produced statistically and educationally significant changes in the basic reading skills of students over and above Corrective Reading alone. Students in the REWARDS condition demonstrated statistically significant mean changes on the WJ-III Basic Reading Skills cluster and associated subtests and the DIBELS ORF probe compared to those in the comparison condition who received CR only. Moreover, effect sizes were moderate in magnitude (i.e., between .5 and .79), suggesting that there was a significant effect on the use of the REWARDS program on students' oral reading fluency. These data indicate that explicit and systematic instruction in word reading strategies has significant additive benefits above such instruction focused on decoding alone.

Our first finding provides preliminary research support for the REWARDS program for diverse middle school students with reading difficulties. The authors of the program conducted preliminary investigations into the approach that align with the findings of the present investigation. In an unpublished investigation, Archer and colleagues (2003) found statistically significant gains on the decoding of words and application of word part identification strategy used with unfamiliar words with middle school youth with reading difficulties (Vachon, 1991; Vachon \& Gleason, 2003). Researchers have highlighted the importance of word study, fluency, vocabulary, and comprehension (Boardman et al., 2008; Carnine et al., 2017; Foorman et al., 2016). REWARDS provide instruction and practice with decoding multisyllabic words, which is critical for success in all content areas, particularly in science and social studies. When struggling middle school readers work with prefixes, suffixes, root words and their meanings, they are better able to comprehend what they read and expand their vocabulary.

Second, middle school youth experiencing reading difficulties need intensive, explicit, and systematic reading instruction beyond core, tier 1 universal instruction. Researchers found that youth achieved more when staff emphasized five explicit and systematic teaching functions during lessons (e.g., Rosenshine \& Stevens, 1986): (a) daily review and prerequisite skill check, (b) teaching of new content, (c) guided youth practice, (d) independent youth practice, and (e) weekly and monthly reviews. Benner et al. (2011) found that these five functions accounted for the variance in the gains of $22 \%$ of basic reading skills and $18 \%$ of passage comprehension in middle school students with 
reading difficulties. In other words, these teaching functions of explicit and systematic instruction made a significant difference in youth responsiveness to secondary and tertiary prevention of reading difficulties (tiers II/III). Researchers have found that systematic and explicit reading instruction provided to struggling readers and those with reading disabilities can improve lifelong literacy outcomes (e.g., Foorman et al., 2016; Partanen \& Siegel, 2013; Wanzek et al., 2015; Wanzek et al., 2018).

\section{LIMITATIONS}

It is important to consider several limitations involved in this study. First, the participants involved in this study are not demographically representative of the general population. Therefore, there is limited generalizability of the results of this study. Future research should include samples of students in varying grade levels. Second, it is unknown if positive results will be maintained. A longitudinal examination of the REWARDS program should be conducted to determine whether the positive effects found in this program are sustainable over time. Third, because social validity was not evaluated, it is unknown whether relevant stakeholders were satisfied with the results of the REWARDS program. Fourth, this study did not include a comparison of student performance while using the Corrective REWARDS program as opposed to another specific reading program. Future research is needed to compare the treatment effects of the REWARDS program to other reading programs. Interpretations should be made cautiously. REWARDS program should be made cautiously. Finally, future research should focus on the impact of REWARDS using true experimental research designs.

\section{IMPLICATIONS}

The findings of this study have several implications for educators. First, the findings underscore the effectiveness of explicit and systematic instruction. Interventions based on such principles effectively addressing key deficit areas, such as phonemic awareness and phonics, are a necessity for students with high-incidence disabilities (U.S. Department of Education, 2002). It may be necessary for teachers to use direct instruction scripted programs. If each classroom teacher attempted to develop their own basic reading skills curriculum, it would not only be time consuming and expensive, but would also come with a high degree of error. There is evidence to support the implementation of scripted direct instruction programs as opposed to teacher-developed methods (Adams \& Engelmann, 1996).

Second, the most important item for educators to remember is delivering the intervention as written with fidelity, or as it is intended to be delivered. It is critical that teachers use error correction procedures, re-teach when students have not mastered content, pace lessons appropriately, provide specific and immediate feedback, complete all parts of the lesson, and follow the lesson script. Sometimes teachers and administrators render a program like REWARDS ineffective or counter-productive when it has simply not been implemented as written (e.g., dosage or amount of instruction) and/or with adequate fidelity. Implementing REWARDS, Corrective Reading, or any other evidence-based reading approach, with low fidelity will likely not yield student growth necessary to close the reading achievement gap. Student 
responsiveness is influenced from applying these interventions with fidelity, enough dosage, and using in-intervention measures to assess reading mastery and fluency. Teachers who deliver standard reading interventions, as written, with at least $90 \%$ fidelity are much more likely to see significant narrowing of the reading achievement gap within one year (Benner, Nelson, Stage, \& Ralston, 2011).

Third, educators should track the progress of students with reading difficulties using fluency-based screening and progress monitoring. The use of in-program mastery measures of student progress is encouraged. Although these measures should not replace progress monitoring using curriculum-based measures, such measures motivate students with EBD through daily goal setting and monitoring. Moreover, such measures provide important data for instructional decisions, such as re-teaching a lesson or task if students do not reach mastery (i.e., correct responses at least $90 \%$ of the time).

Finally, our findings bolster support for data-based individualization (DBI) to meet the literacy needs of middle school students who need intensive literacy supports. DBI is a systematic method for using assessment data to determine when and how to intensify intervention in reading using systematic and frequent collection and analysis of studentlevel data, modification of intervention components, and use of teachers' clinical experience and judgment to individualize intervention (National Center on Intensive Intervention, 2013). In the present investigation we used validated screening tools to identify middle school learners in need of extra literacy supports, used placement testing to determine (diagnose) where to begin instruction withing Corrective Reading Decoding and REWARDS, and used mastery measures and general outcome measures to monitor responsiveness to intervention. Overall, teachers implemented both Corrective Reading and REWARDS with fidelity and adjusted instruction to meet learner needs, based on mastery measure and general outcome data.

\section{Research Implications}

While the need for intervention studies is pressing, we believe that it is important for language instructional interventions to be evaluated with the service delivery context of schools in mind. To this end, there are models of studies of reading interventions conducted with students where literacy instruction approaches, and strategies fit contextually in current school practices (e.g., Lane, 1999; Strong et al., 2004; Nelson et al., 2005). We believe that the usefulness of literacy research conducted with middle school students with reading difficulties should be directed at the service delivery context of schools. More specifically, we believe that researchers should contextualize their reading research within the multi-level and Response to Intervention (RtI) or service delivery instructional (and behavioral) framework being used by schools (e.g., Fuchs et al., 2003). This placement of literacy intervention programs and approaches within such service delivery models would be useful to researchers and educators alike. Like all youth, the reading difficulties of middle school students are best represented with a gradient or dimensional model (i.e., literacy skills fall on a continuum). Effectively improving their literacy skills requires a range of multi-tiered interventions and supports. Researchers should conduct reading research on interventions at the 
secondary (Tier 2) and tertiary (Tier 3) prevention levels within the multi-level prevention framework.

Middle school students with reading difficulties tend not to benefit fully from primary prevention (Tier I) language arts and reading instruction provided in general education, therefore we recommend focusing on these two levels. Tier 2 and 3 programs and practices should be based on three principles of effective instruction (Fuchs et al., 2003). First, Tiers 2 and 3 require an explicit, didactic form of instruction in which the teacher directly guides students to ensure they learn. Explicit instruction involves instruction with a high level of teacher and student interactions. Second, the less visible and observable features of Tier 2 and 3 interventions are instructional design features that comprise the content and skills that are being taught. Well-designed programs anticipate and eliminate potential misunderstandings by means of carefully sequenced and integrated instruction both within and across lessons. Third, Tier 2 and 3 interventions should include embedded instructional management procedures and motivators that help students regulate their attention and behavior and actively engage during instruction given that problem behavior interferes with academic outcomes ( $\mathrm{Al}$ Otaiba \& Fuchs, 2002; Nelson et al., 2003).

In sum, literacy remains one of the most urgent social issues affecting disadvantaged populations in the United States. It is very difficult to achieve economic success and full citizenship in the 21 st century without the ability to read and write. By implementing guidelines for remedial reading within the classroom, along with the implementation of programs such as the Corrective Reading Decoding (CRD) combined with the Reading Excellence: Word Attack \& Rate Development Strategies, adolescent literacy would rise among those who struggle most while and college and career readiness would increase.

\section{REFERENCES}

ACT. (2006). Reading between the lines: What the ACT reveals about college readiness in reading. from http://www.act.org/research/policymakers/pdf/reading_summary.pdf

Adams, G., \& Engelmann, S. (1996). Research on Direct Instruction: 25 years beyond DISTAR. Seattle, WA: Educational Achievement Systems.

Al Otaiba, S., \& Fuchs, D. (2002). Characteristics of children who are unresponsive to early literacy intervention: A review of the literature. Remedial and Special Education, 23, 300-316. https://doi.org/10.1177/07419325020230050501

Archer, A. L., Gleason, M., \& Vachon, V. (2003). REWARDS. Longmont, CO: Sopris West.

Benner, G. J. (2007). The Relative Impact of Remedial Reading Instruction on the Basic Reading Skills of Students with Emotional Disturbance and Learning Disabilities. Journal of Direct Instruction, 7(1), 1-15.

Benner, G. J., Nelson, J. R., Stage, S. A., \& Ralston, N. C. (2011). The influence of fidelity of implementation on the reading outcomes of middle school students 
experiencing reading difficulties. Remedial and Special Education, 32, 79-88. https://doi.org/10.1177/0741932510361265

Benner, G. J., Kinder, D., Beaudoin, K. M., \& Stein, M. (2005). The Effects of the "Corrective Reading Decoding" Program on the Basic Reading Skills and Social Adjustment of Students with High-Incidence Disabilities. Journal of Direct Instruction, 5(1), 67-80.

Boardman, A. G., Roberts, G., Vaughn, S., Wexler, J., Murray, C. S., \& Kosanovich, M. (2008). Effective instruction for adolescent struggling readers: A practice brief. Portsmouth, NH: RMC Research Corporation, Center on Instruction.

Browder, D. M., Gibbs, S., Ahlgrim-Delzell, L., Courtade, G. R., Mraz, M., \& Flowers, C. (2009). Literacy for students with severe developmental disabilities: what should we teach and what should we hope to achieve? Remedial and Special Education, 30, 269-282. https://doi.org/10.1177/0741932508315054

Burke, M. D., Boon, R. T., Hatton, H., \& Bowman-Perrott, L. (2015). Reading interventions for middle and secondary students with emotional and behavioral disorders: a quantitative review of single-case studies. Behavior Modification, 39, 43-68. https://doi.org/10.1177/0145445514547958

Butler, C. M. (2014) The impact of REWARDS on reading skills of students with learning disabilities. Capstone Projects and Master's Theses, 403. https://digitalcommons.csumb.edu/caps_thes/403

Campbell, A. R., Bowman-Perrott, L., Burke, M.D., \& Sallese, M. R. (2018) Reading, writing, math, and content-area interventions for improving behavioral and academic outcomes of students with emotional and behavioral disorders. Learning Disabilities: A Contemporary Journal, 16, 119-138.

Carnine, D., Silbert, J., Kame'enui, E., Slocum, T. A., \& Travers, P. (2017). Direct instruction reading (6th ed.). Boston, MA: Pearson.

Cihak, D. F., \& Smith, C. C. (2018). Teaching academic skills to elementary-age students with intellectual disability. In Instructional strategies for students with mild, moderate, and severe intellectual disability. Los Angeles, CA: Sage.

Cohen, J. (1988). Statistical Power Analysis for the Behavioral Sciences (2nd ed.). Hillsdale, NJ: Erlbaum.

Deno, S. L., Fuchs, L. S., Marston, D. B., \& Shin, J. (2001). Using curriculum-based measurement to establish growth standards for students with learning disabilities. School Psychology Review, 30(4), 507-524.

Dunlosky, J. (2013). Strengthening the Student Toolbox: Study Strategies to Boost Learning. American Educator, 37(3), 12-21. 
Ellis, E. S., \& Graves, A. W. (1990). Teaching rural students with learning disabilities: A paraphrasing strategy to increase comprehension of main ideas. Rural Special Education Quarterly, 10(2), 2-10.

Engelmann, S., Hanner, S., \& Johnson, G. (2002). Corrective reading: Series guide (5 $5^{\text {th }}$ ed.). Columbus, OH: SRA/McGraw-Hill.

Foorman, B.R., Beyler, N.K., Borradaile, K.E., Coyne, M., Denton, C.A., Dimino, J., Furgeson, J.R., Hayes, L., Henke, J., Justice, L.M., Keating, B., Lewis, W., Sattar, S.A., Streke, A., Wagner, R.K., \& Wissel, S. (2016). Foundational skills to support reading for understanding in kindergarten through $3^{\text {rd }}$ grade (NCEE No. 4008). National Center for Education Evaluation and Regional Assistance Working Paper. Washington, DC: U.S. Department of Education.

Fuchs, D., Mock, D., Morgan, P. L., Young, C. L. (2003). Responsiveness-to Intervention: Definitions, evidence, and implications for the learning disabilities construct. Learning Disabilities Research \& Practice, 18, 157-171. https://doi.org/10.1111/1540-5826.00072

Garwood, J.D. (2018). Literacy interventions for secondary students formally identified with emotional and behavioral disorders: trends and gaps in the research. Journal of Behavioral Education, 27, 23 - 52. https://doi.org/10.1007/s10864-017-9278-3

Kamil, M. L., Borman, G. D., Dole, J., Kral, C. C., Salinger, T., \& Torgesen, J. (2008). Improving adolescent literacy: Effective classroom and intervention practices: A Practice Guide (NCEE \#2008-4027). Washington, DC: National Center for Education Evaluation and Regional Assistance, Institute of Education Sciences, U.S. Department of Education. Retrieved from http://ies.ed.gov/ncee/wwc.

Kaminski, R. A., \& Good, R. H., III. (1996). Toward a technology for assessing basic early literacy skills. School Psychology Review, 25, 215-227.

Lane, K. L. (1999). Young students at risk for antisocial behavior: The utility of academic and social skills interventions. Journal of Emotional and Behavioral Disorders, 7, 211-233. https://doi.org/10.1177/106342669900700403

Lee, J., \& Yoon, S. Y. (2017). The effects of repeated reading on reading fluency for students with reading disabilities: A meta-analysis. Journal of learning disabilities, 50(2), 213-224.

Lloyd, J., Cullinan, D., Heins, E. D., \& Epstein, M. H. (1980). Direct Instruction: Effects on Oral and Written Language Comprehension. Learning Disability Quarterly, 3(4), 70-76.

Marchand-Martella, N.E., Martella, R. C., Orlob, M., \& Ebey, T. (2000). Conducting Action Research in a Rural High School Setting Using Peers as Corrective Reading Instructors for Students with Disabilities. Rural Special Education Quarterly, 19(2), 2030. https://doi.org/10.1177/875687050001900204 
Marchand-Martella, N. E., Martella, R. C., Modderman, S. L., Petersen, H. M., \& Pan, S. (2013). Key Areas of Effective Adolescent Literacy Programs. Education and Treatment of Children,36(1), 161-184. https://doi.org/10.1353/etc.2013.0005

Martella, R. C., Nelson, J. R., \& Marchand-Martella, N. E. (1999). Research methods: Learning to become a critical research consumer. Boston: Allyn and Bacon.

National Governors Association Center for Best Practices, Council of Chief State School Officers (2012). Common Core State Standards for English Language Arts. National Governors Association Center for Best Practices, Council of Chief State School Officers, Washington D.C.

Nelson, J. R., Babyak, A., Gonzalez, J. E., Benner, G. J. (2003). An investigation of the types of problem behaviors exhibited by K-12 students with emotional and behavioral disorders in public school settings. Behavioral Disorders, 28, 348-359. https://doi.org/10.1177/019874290302800406

Nelson, J. R., Lane, K. L., Benner, G. J., \& Ockjean, K. (2011). A best evidence synthesis of literacy instruction on the social adjustment of students with or at risk for behavior disorders. Education and Treatment of Children, 34, 141-162. www.jstor.org/stable/42900104

No Child Left Behind Act of 2001, 20 U.S.C. 70 § 6301 et seq. (2002).

Partanen, M., \& Siegel, L. S. (2014). Long-term outcome of the early identification and intervention of reading disabilities. Reading and Writing: An Interdisciplinary Journal, 27, 665-684. https://doi.org/10.1007/s11145-013-9472-1

Przychodzin-Havis, A. M., Marchand-Martella, N. E., Martella, R. C., Miller, D. A., Warner, L., Leonard, B., \& Chapman, S. (2005). An analysis of Corrective Reading research. Journal of Direct Instruction, 5, 37 - 65.

Rumberger, R., Addis, H., Allensworth, E., Balfanz, R., Bruch, J., Dillon, E., ...Tuttle, C. (2017). Preventing drop-out in secondary schools (NCEE 2017-4028). Washington, DC: Institute of Education Sciences, U.S. Department of Education.

Somerville, D. E., \& Leach, D. J. (1988). Direct or indirect instruction? An evaluation of three types of intervention programs for assisting students with specific reading difficulties. Educational Research,30(1), 46-53. https://doi.org/10.1080/0013188880300106

Strong, A. C., Wehby, J. H., Faulk, K. B., \& Lane, K. L. (2004). The impact of a structured reading curriculum and repeated reading on the performance of junior high students with emotional and behavioral disorders. School Psychology Review, 33, 561581 .

Tindal, G., Marston, D., \& Deno, S. L. (1983). The reliability of direct and repeated measurement (Vol. 84). Research Report. 
Thomson, B. (1992). A field report: Specific learning disabilities Corrective Reading pilot study $1989-1990$. ADI News, 11, $11-13$.

University of Oregon Center on Teaching and Learning (2020). UO DIBELS Data System. https://dibels.uoregon.edu/

U.S. Department of Education. Institute of Education Sciences, National Center for Education Statistics, National Assessment of Educational Progress. (2017). The Nation's Report Card: Reading (Rep. No. 2007496).

U.S. Department of Education, Institute of Education Sciences, National Center for Education Statistics, National Assessment of Educational Progress. (2019). 19922019 Reading Assessments.

U.S. Department of Education. (2002). Reading First program state application. Washington, DC: Author.

Voyager Sopris Learning (2020). REWARDS: Explicit, Systematic, Short-Term Literacy Intervention. https://www.voyagersopris.com/literacy/rewards/overview

Wanzek, J., Kent, S. C., Vaughn, S., Swanson, E. A., Roberts, G., \& Haynes, M. (2015). Implementing team-based learning in middle school social studies classes. The Journal of Educational Research, 108(4), 331-344. https://doi.org/10.1080/00220671.2014.893224

Wanzek, J., Stevens, E. A., Williams, K. J., Scammacca, N., Vaughn, S., \& Sargent, K. (2018). Current evidence on the effects of intensive early reading interventions. Journal of Learning Disabilities, 51, 612- 624. https://doi.org/10.1177/0022219418775110

Wexler, J., Vaughn, S., Roberts, G., \& Denton, C. A. (2010). The efficacy of repeated reading and wide reading practice for high school students with severe reading disabilities. Learning Disabilities Research \& Practice, 25(1), 2-10.

White, W. A. T. (1988). A meta-analysis of the effects of Direct Instruction in special education. Education and Treatment of Children, 11(4), 364-374.

Woodcock, R. W., McGrew, K. S., \& Mather, N. (2001). Woodcock-Johnson III: Tests of Achievement. Itasca, IL: Riverside. 